\title{
Fecal Tumor M2-Pyruvate Kinase TM (ScheBo Test) for Colorectal Cancer Detection in Adult Egyptians
}

\author{
Amany Helmy Lashin, Ebada Mohammad Said, Zeiad Samir Gad ${ }^{1}$, \\ Hesham Ali Issa ${ }^{2}$, Rania Zakria Aamer ${ }^{3}$, Abdelmoneam Ahmed ${ }^{4}$, \\ Mahmoud Abd El Aty Mohamed ${ }^{5}$, Sheref M. El-Taher ${ }^{6}$ \\ Departments of Hepatology, Gastroenterology and Infectious Diseases, Benha University; Surgical Oncology, \\ National Cancer Institute, Cairo \\ Clinical and Chemical Pathology, Benha University ${ }^{2}$ \\ Pathology, Benha University ${ }^{3}$ \\ Internal Medicine, Benha University ${ }^{4}$ \\ Internal Medicine, El Sahel Teaching Hospital ${ }^{5}$ \\ Public Health and Community Medicine, Benha University ${ }^{6}$
}

\begin{abstract}
Introduction: Colorectal cancer (CRC) represents the $3^{\text {rd }}$ most common tumor worldwide and the $6^{\text {th }}$ in Egypt. It is still burdened by significant morbidity and mortality despite several therapeutic improvements. A gold standard for early detection and non invasive diagnosis is lacking. Aim was to assess faecal tumor M2-PK (ScheBo test) for detection of CRC.In Adult Egyptians

Methods: This cross-sectional, case-control study was carried out on 66 subjects. The cases group comprised 46 consecutive treatment- naïve patients with sporadic CRC proved by colonoscopy, histopathology and abdominal computed tomography which all together helped in tumor staging with TNM and Duke's staging systems. Twenty apparently healthy subjects (without CRC and with normal colonoscopy) served as the control group (age and sex matching the cases group). Faecal tumor M2-PK ${ }^{\mathrm{TM}}$ (ScheBo test) was assessed in all the study subjects.

Results: Cases were 24 males and 22 females with a mean age of $50.6 y_{s}$ and the range was 22-81 $y_{s}$. Age ditribution showed 12 cases (26\%) below 40 and $50 \%$ above $50 y_{s}$. Bleeding per rectum was the main presenting symptom (39\%) followed by recent onset constipation (34.8\%) in the studied cases. Rectal lesions were found during colonoscopy in $47.8 \%$ of cases while colonic lesions were found in $52.2 \%$. Mass was the most encountered gross pathology (in 67.4\%, 31 cases) followed by ulcer (in 28.3\%, 13 cases) and stricture (in 4.3\%, 2 cases). Adenocarcinoma was the commonest type (76.1\%, 35 cases) followed by mucinous adenocarcinoma $(15.2 \%, 7$ cases $)$. The fecal levels of tumor M2-PK were significantly higher $(P<0.001)$ in cases compared to the control (35.66 \pm 17.32 and $2.74 \pm 4.36 \mathrm{U} / \mathrm{ml}$, respectively). Fecal tumor M2-PK levels showed a significant positive correlation with both TNM and Duke's stages $(p<0.05)$, while no significant correlation was found with age and sex. Applying ROC curve, at a cut-off value of $3.9 \mathrm{U} / \mathrm{ml}$, fecal Tumor M2$P K$ was $97.8 \%$ sensitive and $85 \%$ specific for detection of CRC with AUROC $=0.96$.

Conclusion: Fecal tumor M2-PK was a sensitive and specific marker for detection of CRC at values $\geq 3.9 \mathrm{U} / \mathrm{ml}$ and positively correlated with the tumour grade and stage.
\end{abstract}

Key Words: colorectal cancer, ScheBo Test, M2-PK

\section{Introduction}

Colorectal cancer (CRC) represents the third most common tumor worldwide, and is still burdened by significant morbidity and mortality despite several therapeutic improvements ${ }^{I}$. CRC incidence rates are rapidly increasing due to the effect of many risk factors, including smoking, physical inactivity, obesity, red and processed meat consumption, as well as excessive alcohol intake ${ }^{2}$

In Egypt, CRC is one of the most common malignant neoplasms. Its incidence ranges between 2-6\% of the total number of cancer cases reported annually and it ranks as the sixth most common cancer in both males and females ${ }^{3}$. The median age of CRC cases in Egypt is 48 years for both males and females ${ }^{4}$.

Most cases of CRC develop from polyps. Three types of polyps occur: hamartoma (junior polyp), hyperplastic mucosal proliferation (hyperplastic polyp) and adenomatous polyp. Adenomatous is the only premalignant type, it may be tubular, villous, or tubulovillous, with villous adenomas the most likely to be cancerous. Adenomatous polyps may be either sessile (flat) or pedunculated (stalked), with sessile types being more likely to progress to cancer. Finally, polyps greater than $2.5 \mathrm{~cm}$ are five times more likely to be cancerous than those less than $1.5 \mathrm{~cm}$. Overall, once an adenomatous polyp forms, it takes at least 5 years of growth to 
reach clinical significance, suggesting the need to initiate screening and perform routine follow-up evaluation to identify polyps that are of concern before they become cancerous 5 .

CRC mortality rates can be decreased by early diagnosis through screening. However, the present CRC screening techniques (colonoscopy, fecal occult blood test (FOBT), and serum carcinoembryonic antigen (CEA) testing are limited by their difficulties and costs beside uncertain or delayed results ${ }^{6}$. Hence, the identification of biomarkers that are simple, noninvasive, cost-efficient and reasonably sensitive/specific is urgently needed ${ }^{7}$.

M2-PK is a key enzyme within glycolysis, a process that catalyzes the conversion of phosphoenolpyruvate (PEP) to pyruvate. Depending upon the metabolic functions of the tissues, different isoenzymes of pyruvate kinase are expressed. During tumour formation, the tissue-specific isoenzymes disappear and the pyruvate kinase isoenzyme type M2 is expressed ${ }^{8}$.

The aim of the present study was to assess faecal tumor M2-PK ${ }^{\mathrm{TM}}$ (ScheBo test) as a marker for CRC detection in Adult Egyptian patients

\section{Patients and methods}

This cross-sectional, case-control study was carried out on 66 subjects. The cases group comprised 46 consecutive patients with CRC who were attending the Departments of Hepatology, Gastroenterology and Infectious Diseases and Internal medicine at Benha University Hospital and Surgical Oncology at National Cancer Institute -Cairo, within the period between January 2015 and March 2016. Another 20 apparently healthy subjects (without CRC and with normal colonoscopy) served as the control group (age and sex matching the cases group). The indication for colonoscopy in these subjects was either long history of unexplained abdominal pain and/or altered bowel habits.

The study protocol was approved by the Ethical Committee of Benha Faculty of Medicine, Benha University. Patients with the following criteria were excluded from the study namely; those refusing the written medical consent, pregnant females, patients with familial adenomatous polyposis or hereditary nonpolyposis $\mathrm{CRC}$, those who were undergoing or received chemotherapy and/or radiotherapy, those with inflammatory bowel diseases, primary sclerosing cholangitis and other malignancies. All the studied cases had given an informed written medical consent. They were subjected to thorough history taking, general and abdominal examination as well as per rectal examination, laboratory investigations; namely: stool analysis, complete blood count $(\mathrm{CBC})$, erythrocyte sedimentation rate (ESR), random blood suger (RBS), glycated hemoglobin (Hb A1C), alanine aminotransferase (ALT), aspartate aminotransferase (AST), alkaline phosphatase (ALP), serum albumin, serum bilirubin (total and direct), prothrombin time (PT) and concentration, serum creatinine and blood urea, carcino-embryonic antigen (CEA) and CA 19-9. Sandwich ELISA with two monoclonal antibodies highly specific for human tumour M2-PK (ScheBo®, Biotech Aktiengesellschaft, Germany) was applied for quantitative assessment of fecal tumor M2-PK ${ }^{\mathrm{TM}}$.

Abdomino-pelvic ultrasonography, computed tomography (CT scan) and complete colonoscopy followed by histopathological examination of the biopsied specimens.

Finally, TNM- and Duke's staging systems were applied.

Statistical analysis: was done using SPSS 20, Quantitative data was expressed in Mean \pm Standard Deviation, Qualitative data was expressed in number and percentage. Comparison between groups was done using MannWhitney U and Kruss-Kal Wallis test, The sensitivity and specificity were examined at different cutoff points using ROC curve analysis to determine the best cutoff point as well as the diagnostic power of each test. A P value $<0.05$ was considered statistically significant $(\mathrm{S})$.

\section{Results}

This study evaluated 46 patients with CRC (24 males and 22 females) with mean age of $50.6 \mathrm{y}_{\mathrm{s}}$ and range $22-81 y_{s}$. The 20 healthy controls were 13 males and 7 females with mean age of $54.1 \mathrm{y}_{\mathrm{s}}$ and range of 27 $80 \mathrm{y}_{\mathrm{s}}$. The mean age of male patients $\left(50.3 \mathrm{y}_{\mathrm{s}}\right)$ was relatively (non significantly) younger than that of female patients $\left(51.1 \mathrm{y}_{\mathrm{s}}\right)$. Distribution of age among the studied cases showed $26 \%$ below $40 \mathrm{y}_{\mathrm{s}}$ and $50 \%$ above $50 \mathrm{y}_{\mathrm{s}}$. 


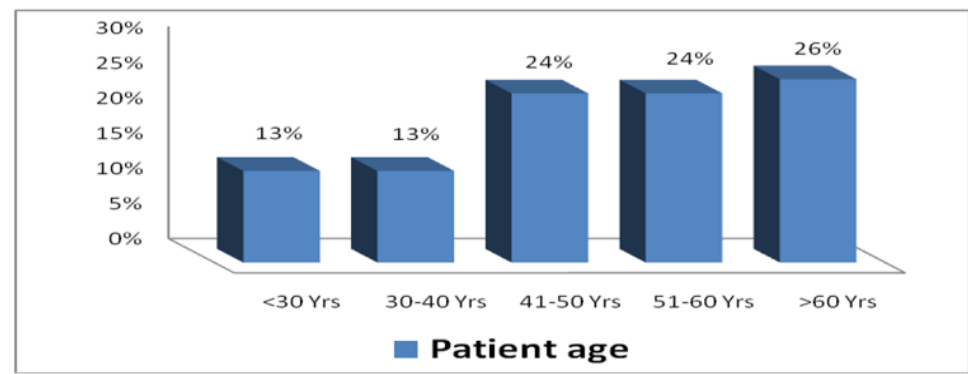

Fig. (1): Age distribution within the studied cases.

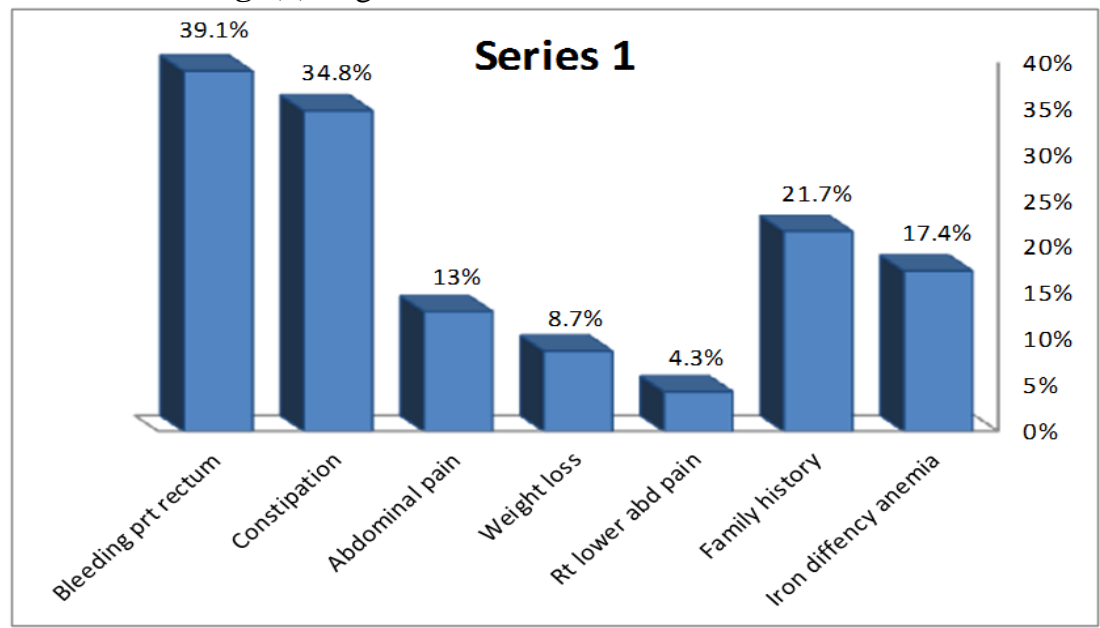

Fig. (2): Presenting symptoms and history findings among the studied cases.

Bleeding per rectum was the main presenting symptom followed by recent onst constipation in the studied cases. Positive family history $\left(1^{\text {st }}\right.$ or $2^{\text {nd }}$ degree relatives) was found in $21.7 \%$ of the studied cases while anemia leading to blood transfusion was found in $17.4 \%$ of them.

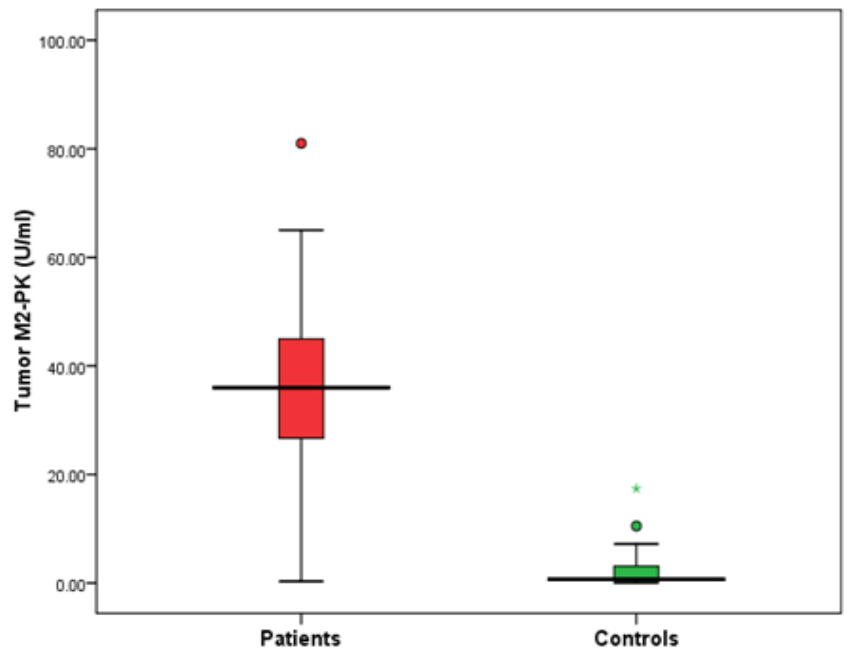

Fig. (3): Fecal Tumor M2-PK level in the studied groups.

The fecal levels of tumor M2-PK were significantly higher $(\mathrm{P}<0.001)$ in the studied cases compared to the control group ( $35.66 \pm 17.32$ and $2.74 \pm 4.36 \mathrm{U} / \mathrm{ml}$ respectively). The median fecal tumor M2-PK level in the control group was $0.7 \mathrm{U} / \mathrm{ml}$ and ranged from $0.02 \mathrm{U} / \mathrm{ml}$ to $17.4 \mathrm{U} / \mathrm{ml}$. The median fecal tumor M2-PK level in cases was $36 \mathrm{U} / \mathrm{ml}$ and ranged from $0.3 \mathrm{U} / \mathrm{ml}$ to $81 \mathrm{U} / \mathrm{ml}$.

Table (1): Fecal M2PK in Diabetes and Smoking.

\begin{tabular}{|l|c|c|c|c|c|c|}
\hline & & No & Mean & S.D & Mann-Whitney U & p-value \\
\hline
\end{tabular}




\begin{tabular}{|c|c|c|c|c|c|c|}
\hline \multirow{2}{*}{ Diabetes } & Diabetic & 22 & 29.06 & 16.44 & \multirow{2}{*}{2.6} & \multirow{2}{*}{0.01} \\
\hline & Non- diabetic & 24 & 41.13 & 16.69 & & \\
\hline \multirow{2}{*}{ Smoking } & Smokers & 26 & 34.79 & 20.04 & \multirow{2}{*}{0.5} & \multirow{2}{*}{0.6} \\
\hline & Non-smokers & 20 & 37.09 & 13.15 & & \\
\hline
\end{tabular}

There was a statistically significant difference in fecal M2PK level between diabetics which is significantly lower $(29.06 \pm 16.44 \mathrm{U} / \mathrm{ml})$ than nondiabetic $(41.13 \pm 16.69 \mathrm{U} / \mathrm{ml})(\mathrm{p}=0.01)$ while a non significant difference was found between smokers $(34.79 \pm 20.04 \mathrm{U} / \mathrm{ml})$ and non-smokers $(37.09 \pm 13.15 \mathrm{U} / \mathrm{ml})$ (p-value 0.6).

Fig (4): Correlation between fecal M2PK and BMI Fig.(4):Correlation be tween fecal M2PK and BMI

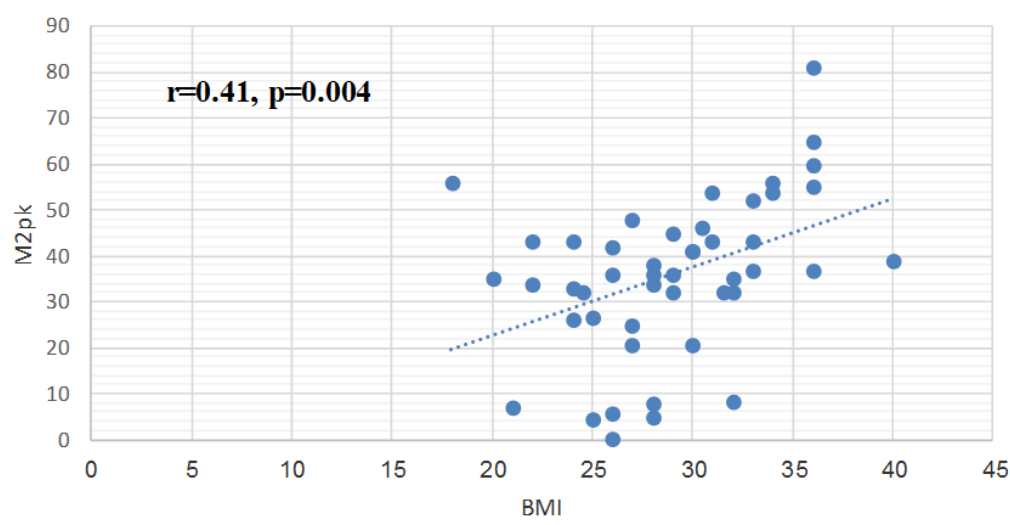

There was a statistically significant positive correlation between fecal M2PK level and BMI in the studied cases $(\mathrm{p}$-value $=0.004)$.

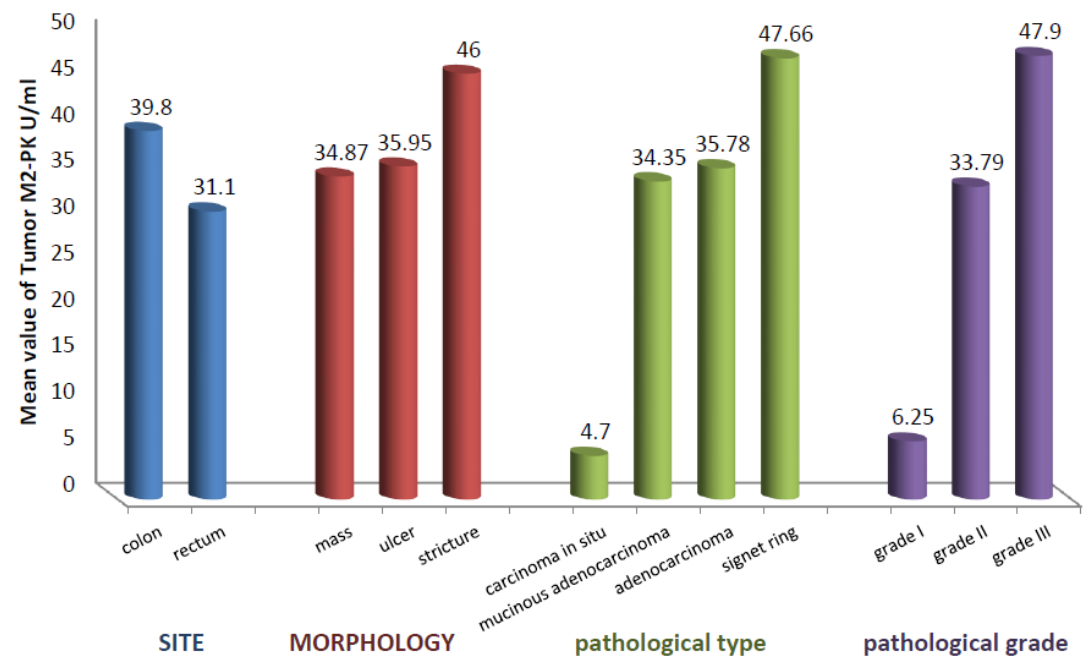

Fig. (5): Mean value of Fecal Tumor M2-PK according to colonoscopic and histopathological findings.

There was no statistically significant difference in fecal Tumor M2-PK levels as regards site, morphology and pathological types of CRC, while there was a statistically significant rise in fecal Tumor M2PK levels as regards pathological grades. The mean value of grade I was $(6.25 \mathrm{U} / \mathrm{ml})$, grade II $(33.79 \mathrm{U} / \mathrm{ml})$ and grade III $(47.9 \mathrm{U} / \mathrm{ml})(\mathrm{P}<0.05)$. The higher the pathological grade of $\mathrm{CRC}$ the higher the mean value of Tumor M2-PK. 
Table (2) and Fig (6) : Fecal Tumor M2-PK levels in different TNM and Dukes stages.

\begin{tabular}{|c|c|c|c|c|c|c|c|}
\hline \multicolumn{2}{|c|}{ Variable } & \multirow{3}{*}{$\begin{array}{l}\mathbf{N}^{\mathbf{0}} \\
3\end{array}$} & \multicolumn{2}{|c|}{ Tumor M2-PK (U/ml) } & \multirow[t]{2}{*}{ KWT test } & \multirow[t]{2}{*}{$\mathbf{P}$} & \multirow[t]{2}{*}{ Sig pairs } \\
\hline & & & Mean \pm SD & Range & & & \\
\hline \multirow{4}{*}{ T stage } & Tis/ T1 & & $11.80 \pm 10.88$ & $4.7-5.1$ & \multirow[t]{4}{*}{10.2} & \multirow[t]{4}{*}{$0.017(\mathrm{~S})$} & \multirow{4}{*}{$\begin{array}{l}\text { Tis/T } 1 \neq \mathrm{T} 3 \\
\text { Tis/T } 1 \neq \mathrm{T} 4\end{array}$} \\
\hline & T2 & 18 & $31.87 \pm 13.75$ & $4.5-54$ & & & \\
\hline & T3 & 23 & $40.23 \pm 17.68$ & $0.3-81$ & & & \\
\hline & T4 & 2 & $53.00 \pm 9.89$ & $46-60$ & & & \\
\hline \multirow{3}{*}{ N stage } & No & 26 & $30.40 \pm 14.03$ & $0.3-54$ & \multirow[t]{3}{*}{10.7} & \multirow{3}{*}{$\begin{array}{c}0.006 \\
(\mathrm{~S})\end{array}$} & \multirow[t]{3}{*}{$\mathrm{N} 0 \neq \mathrm{N} 2$} \\
\hline & N1 & 11 & $38.80 \pm 15.73$ & $4.5-65$ & & & \\
\hline & N2 & 8 & $52.32 \pm 17.30$ & $20.6-81$ & & & \\
\hline \multicolumn{2}{|c|}{ Duke A } & 3 & $12.70 \pm 10.88$ & $4.7-25.1$ & \multirow[t]{4}{*}{7.15} & \multirow[t]{3}{*}{$0.028(\mathrm{~S})$} & \multirow{3}{*}{$\begin{array}{l}\mathrm{A} \neq \mathrm{B} \\
\mathrm{A} \neq \mathrm{C}\end{array}$} \\
\hline & & 24 & $33.33 \pm 15.47$ & $0.3-60$ & & & \\
\hline \multirow{2}{*}{\multicolumn{2}{|c|}{ Duke C }} & \multirow[t]{2}{*}{19} & \multirow[t]{2}{*}{$42.23 \pm 17.03$} & \multirow[t]{2}{*}{$4.5-81$} & & & \\
\hline & & & & & & & \\
\hline
\end{tabular}

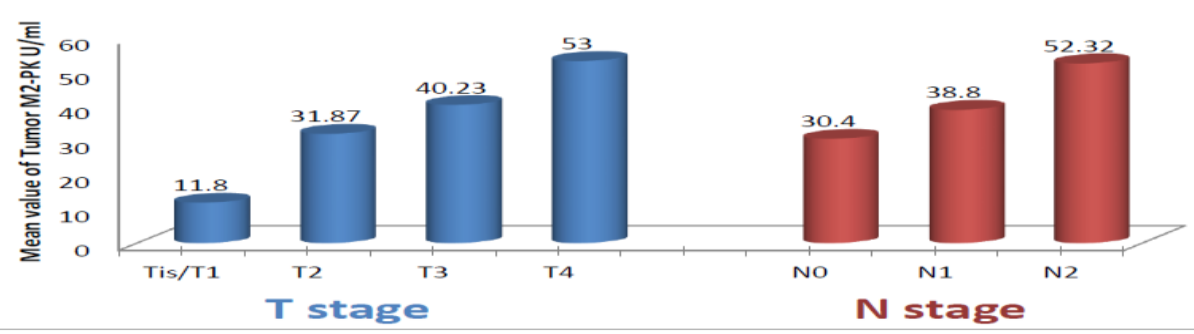

There was a statistically significant difference in fecal Tumor M2-PK levels in different TNM Stages. There was also a significant difference in fecal Tumor M2-PK levels in different Dukes stages. $(\mathrm{P}<0.05)$.

Table (3) and Fig. (7): ROC curve for the performance of Tumor M2-PK in detection of CRC.

\begin{tabular}{|c|c|c|c|c|c|c|c|}
\hline Tumor M2-PK U/ml & Sens\% & Spec\% & PPV\% & NPV\% & AUC & $95 \%$ CI & P \\
\hline$\geq 3.9$ & $97.8 \%$ & $85 \%$ & $93.8 \%$ & $94.4 \%$ & 0.96 & $0.92-1.0$ & $<0.001$ (HS) \\
\hline
\end{tabular}

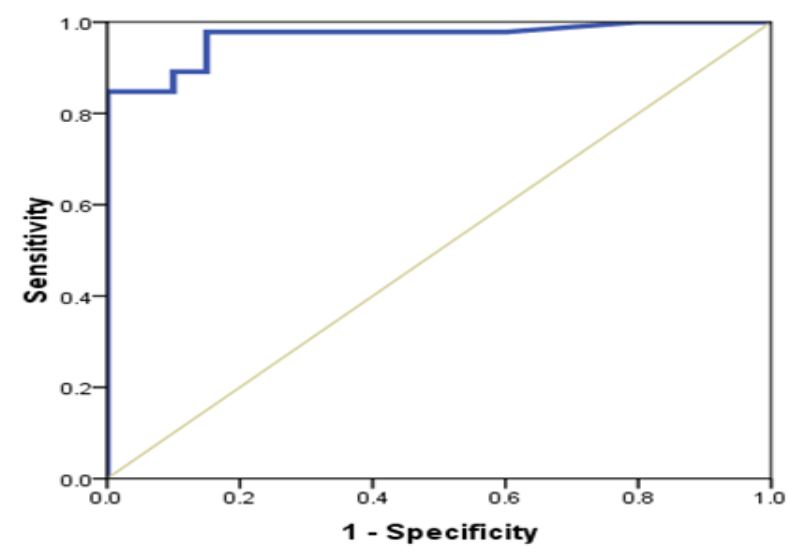

At a cut-off value of $3.9 \mathrm{U} / \mathrm{ml}$, fecal Tumor M2-PK was $97.8 \%$ sensitive and $85 \%$ specific for detection of CRC with $\mathrm{AUROC}=0.96$. 
Fig (8) and Table (4): ROC curve for the performance of different markers in detection of CRC.

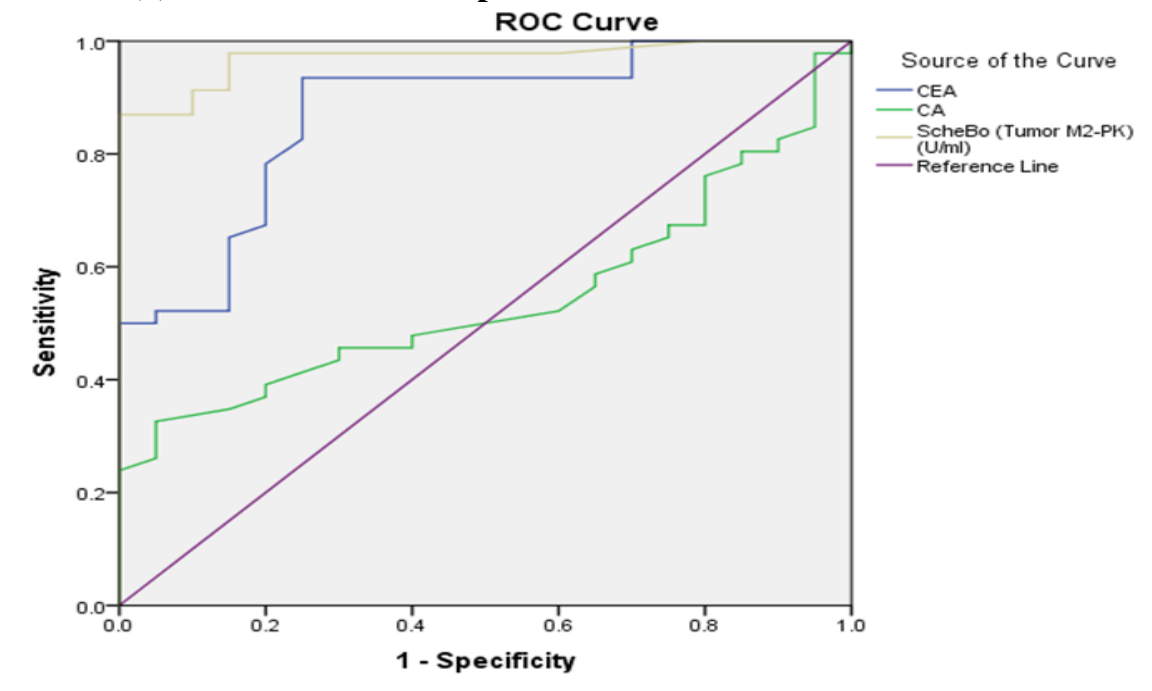

\begin{tabular}{|c|c|}
\hline \multicolumn{1}{|l|}{ Tumour markers } & AUROC \\
\hline CEA & 0.871 \\
\hline CA19-9 & 0.543 \\
\hline ScheBo (Tumor M2-PK) (U/ml) & $\mathbf{0 . 9 7 1}$ \\
\hline
\end{tabular}

ROC curve reveals that Tumor M2-PK was better than CEA and CA 19.9 in detection of CRC at any stage.

\section{Discussion}

In the present study, the age of the studied cases ranged between $22-81 \mathrm{ys}$, with a mean of $50.6 \pm$ 15.1 ys. Fifty percent were $>50 \mathrm{ys}$ and $26 \%$ (more than $1 / 4$ of patients) were $\leq 40 \mathrm{ys}$. This comes in agreement with ${ }^{(9,10)}$ who found that the mean age of their assessed Egyptian patients was 51ys and 44.8ys respectively. $\boldsymbol{E l}$ Attar, (2005) and Sakr et al., (2016) told that the median age of CRC patients in Egypt was 48 and 51.2 ys respectively ${ }^{(5,10)}$. Basu et al., (2016) and Nataraj et al., (2016) found the mean age of their assessed Indian patients was $52.8 \pm 13.5$ and $49.31 \mathrm{ys}$, respectively ${ }^{(11,12)}$. On the other hand; ${ }^{(13)}$ found that the mean age of their assessed American Non-Hispanic white and American Asian patients was $70.3 y s$ and 66.3ys respectively. ${ }^{(13)}$ while $^{(14)}$ found that the median age of CRC cases was 70 years in Germany ${ }^{(14)}$.

About $1 / 4$ of the assessed cases in the current study were below the age of 40 ys. This comes in agreement with ${ }^{(9,15,16,17)}$ who found that CRC cases under the age of $40 \mathrm{ys}$ were $35.6 \%, 25 \%, 22 \%, 38 \%$ and one third respectively in their studied Egyptian patients. In Asia, ${ }^{(18)}$ told that $19.5-28.6 \%$ of patients were less than 40ys and in Mexico, National Cancer Institute reported $22.8 \%$. On the contrary, ${ }^{(19)}$ in USA, mentioned that CRC is rare before age 40ys in both men and women. $\left.{ }^{(20}\right)$ told that CRC is rare before the age of 40 except for those with genetic predisposition or predisposing conditions and mentioned that the frequency of CRC in patients less than 40 ys in USA, France, Australia and Denmark was 6-7\%, 3.1\%, $5 \%$ and $2.5 \%$ respectively. The difference in mean ages could be attributed to different risk factors, dietary patterns, life style and life expectancy in different cultures and societies. This finding may enhance the need for early screening for CRC among the Egyptian population. ${ }^{(18)}$

Males represented $52.2 \%$ (and females, $47.8 \%$ ) of the studied cases in the present study, with no statistically significant difference $(p>0.05)$. This comes in agreement with ${ }^{(10,21,22,23)}$ who told that CRC affects men and women almost equally. In disagreement with this, ${ }^{(24,25)}$ told that men have more incidence of CRC than women. The percentage of the studied cases with CRC with a positive family history was $21.7 \%$. This comes in agreement with ${ }^{(26,27)}$ who told a percentage of up to $20 \%$. ${ }^{(28)}$ reported a higher figure $(31.3 \%)$ in Iranian patients. These data make adherence to CRC screening programs mandatory in subjects with family history of CRC.

In the present study, bleeding per rectum was the commonest presenting symptom (39.1\%) followed by recent onset constipation (34.8\%) which is concomitant with the local reports of ${ }^{(29}$ ) who met bleeding per rectum as the main presenting symptom of their studied cases. 
Mass was the commonest gross pathology $(67.4 \%)$ detected in the studied cases followed by ulcer 28.3 $\%$ and stricture $4.3 \%$. This comes in agreement with ${ }^{(23)}$ who found that fungating mass was the main colonoscopic picture in $86.2 \%$ of cases. In the present study, as regards the tumors site, rectal carcinoma (47.8 $\%$ ) was nearly equal to colonic $(52.2 \%)$. This agrees with ${ }^{(17,30)}$ who told that about half of their studied cases were rectal lesions. On the other hand, ${ }^{(13)}$ reported a lower incidence of rectal lesions $(25.5-30.5 \%)$ compared to colonic, while Khafagy and his colleagues, (2000) reported that rectal carcinoma was more common (68\%) than colonic ones.

Upon histopathological examination, most of the studied cases in the present study were adenocarcinoma $(76.1 \%$ ), mucinous and signet ring adenocarcinomas constituted only $21.7 \%$. This comes in agreement with ${ }^{(31)}$ who found that histologic tumor type was predominantly adenocarcinoma $(78.5 \%)$ while the more aggressive mucinous and signet ring adenocarcinomas constituted only (21.5\%)of their studied cases. This was also in agreement with ${ }^{(8,10,15,32)}$. In the current study, The fecal levels of tumor M2-PK were significantly higher $(\mathrm{P}<0.001)$ in the studied cases with $\mathrm{CRC}(35.66 \mathrm{U} / \mathrm{ml})$ than in the control group $(2.74$ $\mathrm{U} / \mathrm{ml})$. This was in agreement with, ${ }^{(14,33,34,35)}$. The median fecal tumor M2-PK level in the control group was 0.7 $\mathrm{U} / \mathrm{ml}$ (range $0.02-17.4 \mathrm{U} / \mathrm{ml}$ ) and in the studied cases was $36 \mathrm{U} / \mathrm{ml}$ (range $0.3-81 \mathrm{U} / \mathrm{ml}$ ). These findings come close to what was found by ${ }^{(36,14,34)}$ who found that the median fecal tumor M2-PK level in the control group was 0.8, 2.10 and $1.75 \mathrm{U} / \mathrm{ml}$, respectively; and the median level in CRC patients was 14.7, 22 and $11.72 \mathrm{U} / \mathrm{ml}$, respectively.

In the present study, at a cut-off value of $3.9 \mathrm{U} / \mathrm{ml}$, fecal tumor M2-PK was $97.5 \%$ sensitive and $85 \%$ specific for diagnosis of CRC with an AUROC $=0.96 .{ }^{(37)}$ reported that M2PK had a sensitivity ranging from $(73-97 \%)$ and specificity from $(78.6-100 \%) .{ }^{(14)}$ told that the high sensitivity of the tumor M2-PK test is due to its ability to detect bleeding and non-bleeding tumors. From a practical point of view, the use of a single random formed stool sample for tumor M2-PK analysis, without requiring dietary restrictions, might be of greater patient convenience. ${ }^{(14)}$ The present study found that fecal tumor M2PK $\square \mathbf{3 6 . 5}$ U/ml could significantly discriminate cases with grade III adenocarcinoma with $90 \%$ sensitivity and $63.9 \%$ specificity, with AUROC $=0.76$, while at level $\square \mathbf{2 5 . 7} \mathbf{~ U / m l}$ it could significantly discriminate cases with Duke stage $>$ A with $83.7 \%$ sensitivity and $100 \%$ specificity, with AUROC $=0.89$. At level $\square \mathbf{3 5 . 5} \mathbf{U} / \mathbf{m l}$ it could significantly discriminate cases $>$ T2 with $68 \%$ sensitivity and $61.9 \%$ specificity, with AUROC $=0.71$, and at level $\square \mathbf{5 0}$ $\mathbf{U} / \mathbf{m l}$, it could significantly discriminate cases $>\mathrm{N} 1$ with $75 \%$ sensitivity and $89.2 \%$ specificity, with AUROC $=0.83$.this is in agreement with ${ }^{(14,34)}$

Fecal tumor M2-PK level showed a statistically significant positive correlation with the pathological grades. The mean value of grade I was $(6.25 \mathrm{U} / \mathrm{ml})$, grade II $(33.79 \mathrm{U} / \mathrm{ml})$ and grade III $(47.9 \mathrm{U} / \mathrm{ml})(\mathrm{P}<0.05)$. This was in agreement with ${ }^{(14,33)}$

In the present study, the mean value of fecal tumor M2-PK level showed a statistically significant difference between different TNM stages $(\mathrm{P}<0.05)$ with a statistically significant positive correlation. The mean values in T1, T2, T3 and T4 were 11.80, 31.87, 40.23 and $53 \mathrm{U} / \mathrm{ml}$, respectively. This comes in agreement with ${ }^{(33)}$ who found the mean value of T1, T2, T3 and T4 were 11.1, 23.8, 55.5 and $132.7 \mathrm{U} / \mathrm{ml}$, respectively.

The mean value of fecal tumor M2-PK level showed a statistically significant difference between different Duke's stages $(\mathrm{P}<0.05)$ in the present study with a statistically significant positive correlation. The mean values in Duke's A, B and C were 12.7, 33.33 and $42.23 \mathrm{U} / \mathrm{ml}$, respectively. This was similar to ${ }^{\text {(33) }}$ who found the mean value of Duke's A, B and C were 19.4, 31.5 and $57.1 \mathrm{U} / \mathrm{ml}$, respectively

In the current study, there was a statistically significant correlation between Tumor M2-PK level with BMI and diabetes mellitus. M2-PK levels were significantly lower in diabetic patients than non-diabetics but no significant correlation with smoking. This was in agreement with ${ }^{(38)}$. In the current study, no statistically significant correlation was found between Tumor M2-PK level and either age or sex. This comes in agreement with ${ }^{(32)}$ who assessed 32 CRC patients with a median age $66 \mathrm{Ys}$ (male to female ratio was 3:1) and found no association between fecal tumor M2-PK level and patients' age or sex.

In the present study, there was a statistically significant negative correlation between tumor M2-PK level and serum albumin in the studied cases $(r=-0.33$ and $\mathrm{P}<0.05)$. This is in agreement with ${ }^{(34)}$. In the present study, there was a statistically highly significant positive correlation between tumor M2-PK level and both serum CEA and CA19-9 levels. However, fecal M2-PK was more sensitive than CEA and CA19.9 in detection of CRC. This comes in agree with ${ }^{(\mathbf{3 9}, 40)}$ who said When other biomarkers such as CA19-9, CEA and M2-PK were compared, the sensitivity of M2-PK was 70\%. But M2-PK showed the best results in CRC with a higher sensitivity when compared with CEA and CA19-9. They also concluded that M2-PK should be used in

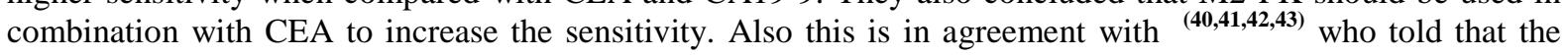
pooled sensitivity of CEA for diagnosis of CRC was only $46 \%$ and the specificity was $89 \%$.

\section{References}


[1] Gellad ZF and Provenzale D, (2010): Colorectal cancer: national and international perspective on the burden of disease and public health impact.Gastroenterology; 138(6): 2177-2190.

[2] Jemal A, Bray, F, Center MM (2011): Global cancer statistics. CA: a cancer journal for clinicians; 61(2): 69-90.

[3] Zalata HR, Tang C, Ming S (2000): Colorectal carcinoma: Pathological study of 83 schistosoma and non-schistosoma associated Egyptian patients. Arab Journal Gastroenterology; 1 (2):178-186.

[4] Zeeneldin AA, Saber M M, Seif El-Din IS (2012): Colorectal carcinoma in Gharbiah District, Egypt: Comparison between the elderly and non-elderly. Journal of Solid Tumors; 2(3):13-23.

[5] El-Attar I, (2005): Colo-Rectal Cancer: Magnitude of the Problem. Annual Cancer Conference of the Egyptian Cancer Society, Danish Cancer Society \& Aarhus University Hospital, Cairo, 9-11 February.

[6] Michael Steinberg (2012): Colorectal Screening Guidelines Update. US Pharm; 37 (12):22-26.

[7] Foo AS, Thia JJ, Fong NP, Koh GC. (2012): Colorectal Cancer Screening: The Effectiveness of Education on Its Barriers and Acceptability. Asia Pac J Public Health. [Epub ahead of print].

[8] Said M, Khairy M, El-Hendawy A (2013): Lack of estrogen receptors expression in malignant and pre-malignant colorectal lesions in Egyptian patients. Open Journal of Gastroenterology ;3 (2013) 155-163.

[9] Gado A, Ebeid B, Abdelmohsen A (2014): Colorectal cancer in Egypt is commoner in young people: Is this cause for alarm?. Alexandria Journal of Medicine; 50(3): 197-201.

[10] Sakr SA, Abdel-Wahed MM, Abdou AG ,(2016): Histochemical alterations in colorectal carcinoma and adenoma in Egyptian patients. Journal of Coastal Life Medicine ; 4(1): 14-20.

[11] Basu A, Seth S, Chauhan AK., (2016): Comparative study of tumor markers in patients with colorectal carcinoma before and after chemotherapy. Annals of Translational Medicine; 4(4):71

[12] Nataraj, S. M., Prema, C. L., Vimalambike, M. G (2016): Major Protein of Carcinoembryonic Antigen Gene Family-CD66c, A Novel Marker in Colon Carcinoma. Journal of Clinical and Diagnostic Research: JCDR; 10(2): XC01-XC04.

[13] Yi M, Xu J, Liu P (2013): Comparative analysis of lifestyle factors, screening test use, and clinicopathologic features in association with survival among Asian Americans with colorectal cancer. British journal of cancer; 108(7): 1508-1514.

[14] Tonus C, Neupert G, Sellinger M. (2006): Colorectal cancer screening by noninvasive metabolic biomarker fecal tumor M2PK. World J Gastroenterol.; 12:7007-11.

[15] Veruttipong D, Soliman AS, Gilbert SF ( 2012) :Age distribution, polyps and rectal cancer in the Egyptian population-based cancer registry. World Journal Of Gastroenterology,; 14; 18(30):3997-4003.

[16] Abou Zeid A.A, Khafagy W, Marzouk D.M, Alaa A, MostafaI, Ela M.A (2002): Colorectal cancer in Egypt. Dis Colon Rectum; $1255-60$.

[17] Soliman A.S, Bondy M.L, Hamilton S.R, (1999): Colon cancer in young Egyptian patients. Am J Gastroenterol: 1114.

[18] Rojas-Puentes L, Garza-Salazar JG, Calderillo-Ruíz G., (2014): Increased Incidence of Colorectal Cancer in Young People (Less Than 40 Years Old) Over the Last Ten Years. Journal of Cancerology;1:16-22.

[19] Howlader N, Noone A.M, Krapcho M, (2011): SEER Cancer Statistics Review, 1975-2008, National Cancer Institute. Bethesda.

[20] Khuhaprema T and Srivatanakul P (2008): Colon and rectum cancer in Thailand: an overview. Japanese journal of clinical oncology; 38(4): 237- 243

[21] Abotchie PN, Vernon SW and Du XL, (2012): Gender differences in colorectal cancer incidence in the United States, $1975-2006$. Journal of Women's Health; 21(4): 393-400.

[22] El-Bolkainy N, Nouh A and El-Bolkainy T, (2006): General pathology of cancer, 4th Edition, edited by Nabil El-Bolkainy, published by Journal of The Egyptian National Cancer Institute, Vol. 17, No. 3, , pp: 33- 42. Farrington S M, Tenesa A, Barnetson R et al.,

[23] Zakaria MS, Hashem A, Abdelbary MS, (2006): The pattern of colonic diseases in Egypt: a colonoscopic study. Arab J Gastroenterol; 7(2): 53-58.

[24] Murphy G, Devesa S S, Cross A J., (2011): Sex disparities in colorectal cancer incidence by anatomic subsite, race and age. International Journal of Cancer; 128(7): 1668-1675.

[25] Rim SH, Seeff L, Ahmed F., (2009): Colorectal cancer incidence in the United States, 1999- 2004. Cancer;115(9): 1967-1976.

[26] Chan JA, Meyerhardt JA, Niedzwiecki D, (2008). Association of family history with cancer recurrence and survival among patients with stage III colon cancer. JAMA; 299: 2515-23.

[27] Haggar FA and Boushey RP, (2009): Colorectal cancer epidemiology: incidence, mortality, survival, and risk factors. Clinics in colon and rectal surgery; 22(4): 191

[28] Fatemi SR, Malek FN and Shivarani S (2010): Prevalence of Colorectal Cancer in Relatives of Iranian Patients Diagnosed with Colorectal Cancer. Asian Pacific J Cancer Prev, 10, 91-93.

[29] Zakaria M, Abdel Wahab A, Kassem A (Thesis) (2010):P53 Mutations in Tissue and Blood in Egyptian Patients With Colorectal Carcinoma and Premalignant Colonic lesions.

[30] Kenawi MM, El-saied A, El-Bolkainy N (1990): Relative frequency of gastrointestinal malignancies at NCI during 14 years (19761989). Med J Cairo Uni; 58: 35-41

[31] Khafagy W, El-Ghazaly M, E-Shobaky MT (2000): Colorectal Cancer in Egypt-Does it Differ?. Coloproctology; 22(3): 109-115.

[32] Hamilton SR, Bosman FT, Boffetta P(2010): Carcinoma of the colon and rectum. In: WHO Classification of Tumours of the Digestive System. Bosman FT, Carneiro F, Hruban RH, Theise ND, eds. Lyon: IARC Press, 134-46.

[33] Hardt PD, Ngoumou BK, Rupp J (2000). Tumor M2-pyruvate kinase: a promising tumor marker in the diagnosis of gastrointestinal cancer. Anticancer Res;20:4965-8.

[34] Koss K, Maxton D and Jankowski JA (2008): Faecal dimeric M2pyruvate kinase in colorectal cancer and polyps correlates with tumour staging and surgical intervention. Colorectal Dis; 10: 244-248.

[35] Parente F, Marino B, Ilardo A (2012): A combination of faecal tests for the detection of colon cancer: a new strategy for an appropriate selection of referrals to colonoscopy? A prospective multicentre Italian study. European journal of gastroenterology \& hepatology; 24(10): 1145-1152.

[36] Shastri YM, Naumann M, Oremek GM, (2006): Prospective multicenter evaluation of fecal tumor pyruvate kinase type M2 (M2PK) as a screening biomarker for colorectal neoplasia. Int J Cancer.; 119:2651-6.

[37] Sithambaram S, Hilmi I and Goh K L, (2015): The Diagnostic Accuracy of the M2 Pyruvate Kinase Quick Stool Test-A Rapid Office Based Assay Test for the Detection of Colorectal Cancer. PloS one; 10(7): 0131616

[38] Schneider J, Morr H, Velcovsky HG, (2000). Quantitative detection of tumor M2-pyruvate kinase in plasma of patients with lung cancer in comparison to other lung diseases. Cancer Detect Prev;24:531-5.

[39] Hardt PD, Mazurek S, Toepler M (2004):Faecal tumour M2 pyruvate kinase: a new sensitive screening tool for colorectal cancer. Br J Cancer.; 91:980-4. 
[40] Liu Z, Zhang Y, Niu Y (2014): A systematic review and meta-analysis of diagnostic and prognostic serum biomarkers of colorectal cancer. PloS one; 9(8): e103910

[41] Xi Wang, Ye-Ye Kuang, and Xiao-Tong Hu (2014): Advances in epigenetic biomarker research in colorectal cancer, World J Gastroenterology.; 20 (15): 4276-4287.

[42] Gupta V and Bamezai R N (2010): Human pyruvate kinase M2: a multifunctional protein. Protein science; 19 (11): 2031-2044.

[43] El-Badry AI, Abdalla MN, Aref WM,(2012):Prevalence of colonic polyps among Egyptians, retrospective study. Jam Sci 2012; 8(11): 394-6. 